EGU2020-8526

https://doi.org/10.5194/egusphere-egu2020-8526

EGU General Assembly 2020

(c) Author(s) 2021. This work is distributed under

the Creative Commons Attribution 4.0 License.

\title{
Assessing UAV survey performance for geomorphological monitoring of mountain rivers
}

Bob de Graffenried, Ivan Pascal, Tomas Trewhela, Valentina Martinez, and Christophe Ancey

LHE, Ecole Polytechnique Fédérale de Lausanne, Lausanne, Switzerland (bob.degraffenried@epfl.ch)

Characterising morphological changes in mountain areas is of fundamental importance for science and engineering. Intense floods usually involve massive sediment transport, which may significantly

alter basin and river characteristics. Sediment erosion and deposition control the dynamics of morphological structures such as alternate bars and meanders. By using unmanned aerial vehicles

(UAV), it has been possible to obtain high-precision bed elevation data at the sediment scale.

Our project aims to develop a consistent and optimised methodology for monitoring morphological

changes in an Alpine watershed using an UAV. Since 2017, we have been monitoring the Plat de la Lé area drained by the River Navisence (Zinal, canton Valais, Switzerland). In mountainous regions, poor accessibility and light conditions make it difficult to set control points on the ground. We first analysed the relevance and influence of certain ground control points (GCP) on the the accuracy of the digital elevation model (DEM) obtained from the UAV's images. Errors in the GCP localisation were much larger than the DEM resolution. Not only did the GCP number and flight height affect these errors, as expected, but their positions and orientations also played a part. We then carried out an additional monitoring campaign to understand the influence of these parameters on the DEM

accuracy. This campaign was ran on two areas: a steep-slope area with irregular topography and a low-slope area that comprises the river channel and its floodplain. We built DEMs for each area considering different GCP numbers (in the 3-18 range with 14 additional checkpoints) and flight heights (in the 40-140-m range). The present study provides guidelines, including an optimal combination

of parameters that significantly reduce errors in the DEM, and a methodology that can be used for monitoring Alpine watersheds on a regular basis. 